\title{
Carro-biblioteca: redesign centrado no usuário de biblioteca pública itinerante
}

\author{
Library car: user-centered redesign of a mobile public library
}

\author{
PEREIRA, Andréa F.; Doutora; Universidade Federal de Minas Gerais \\ andreafranco@ufmg.br \\ DE MARTINO, Letícia R.; Graduanda; Universidade Federal de Minas Gerais \\ martinoleticia96@ufmg.br \\ LIMA, Nathalia C.; Graduanda; Universidade Federal de Minas Gerais \\ nathaliacarvalholima@gmail.com
}

FERREIRA, Viviane P. P.; Bibliotecária; Secretaria de Estado de Cultura de Minas Gerais

cb.sub@cultura.mg.gov.br

VELOSO, Gildete A. S. S.; Bibliotecária; Secretaria de Estado de Cultura de Minas Gerais

dear.sub@cultura.mg.gov.br

\section{Resumo}

Este artigo apresenta os resultados de investigação realizada junto aos usuários para o redesign de um "carro-biblioteca", que tem a função de levar o acervo da Biblioteca Pública Estadual de Minas Gerais até comunidades socialmente vulneráveis que não possuem bibliotecas ou equipamentos culturais, democratizando o acesso à leitura. $O$ trabalho baseou-se na aplicação de técnicas que permitissem ampla compreensão quanto às necessidades dos usuários do Carro-Biblioteca, compreendidos em duas categorias: "atendentes" e "leitores". As técnicas empregadas dizem respeito à vivência aprofundada do cotidiano de atendimento do Carro-Biblioteca e à problematização da experiência dos usuários. Os resultados alcançados nessas análises constituem os fundamentos das soluções a serem implantadas no novo Carro-Biblioteca.

Palavras Chave: Design; Biblioteca Itinerante; Usuário; Metodologia.

\begin{abstract}
This article presents the results of research carried out with the users to redesign a "library car", whose objective is to take the collection of the State Public Library of Minas Gerais to socially vulnerable communities that do not have libraries or cultural equipment, democratizing access to reading. The work was based on the application of techniques that allowed a wide understanding of the needs of the mobile library users, in two categories: "attendants" and "readers". The techniques used are related to the in-depth experience of the daily Library Car service and to the problematization of the users' experience. The results achieved in these analyzes constitute the foundations of the solutions to be implemented in the new Library Car.
\end{abstract}

Keywords: Design; Mobile Library; User; Methodology. 


\section{Introdução}

O serviço de Carro-Biblioteca da Biblioteca Pública Estadual de Minas Gerais foi criado em 1960. Desde então, vem desempenhando o papel de veículo de difusão de leitura e informação junto aos bairros com altos índices de vulnerabilidade socioeconômica, comunidades estas que não possuem bibliotecas ou equipamentos culturais. O Carro-Biblioteca vem disponibilizando para empréstimo acervo informativo e literário. Em sua trajetória atendeu às necessidades de leitura e informação de várias comunidades e promoveu diversas modalidades de ações culturais, tais como "Hora do Conto e da Leitura", "Roda de Leitura", "Encontro com Escritor", "Oficina de Produção de Texto" entre outras. Tornou-se uma referência cultural para os bairros atendidos pelo seu serviço.

Atualmente, seis comunidades recebem a visita do Carro-Biblioteca uma vez por semana. Segundo os registros da Biblioteca Pública Estadual, mais de 37 bairros já foram beneficiados pelo serviço. A cada ano, percebe-se um aumento gradativo do número de novos leitores inscritos e também dos empréstimos realizados.

Os países que valorizam a educação como fator de transformação socioeconômica incentivam a competência leitora como um direito de todos. Essas nações continuam a ver a biblioteca - pública, popular ou comunitária, ou qualquer outra designação que acervos coletivos venham a ter - como um lugar adequado para o "encontro" do leitor com o livro. É um espaço de pluralidade, de diversidade e de liberdade de escolha. No Brasil, apesar da diminuição do analfabetismo nas últimas décadas, ainda há muito a ser feito para que o País seja considerado uma nação leitora. Há que se desenvolver estratégias e ações culturais que diminuam a distância entre o mundo literário e a massa de cidadãos excluídos da dinâmica da sociedade do conhecimento.

No Brasil, onde o poder aquisitivo médio da população não permite que livros façam parte da cesta básica da grande maioria das famílias, o acesso à leitura somente é possível por meio de bibliotecas de acesso público. Crianças e jovens matriculados na rede de ensino, pública ou particular, contam com bibliotecas escolares. À população que não mais integra a comunidade escolar, restam as bibliotecas públicas e comunitárias como única possibilidade. Belo Horizonte não destoa do panorama das bibliotecas de acesso público do País. Esta capital com dois milhões e meio de habitantes, conta com uma rede muito pequena e tímida de bibliotecas públicas em relação ao seu número de habitantes (a UNESCO recomenda uma biblioteca por 12 mil habitantes). Nesse contexto, a ação do Carro-Biblioteca constitui uma significativa contribuição para melhorar o acesso ao conhecimento.

O primeiro veículo utilizado para o Carro-Biblioteca foi um ônibus adaptado, que atendeu ao serviço de biblioteca móvel no período de 1960 a 1976. No ano seguinte foi substituído por um caminhão baú, especialmente adaptado para comportar o acervo. Em 2007 o baú do caminhão passou por uma revitalização, que permitiu o acondicionamento de um acervo maior: em torno de 3.500 livros dos mais variados assuntos entre auto-ajuda, religião, filosofia, biografias, enciclopédias, dicionários, periódicos (jornais e revistas) entre outros, com ênfase em obras de literatura para adultos, jovens e crianças. O veículo atual (Figura 1) foi fabricado em 1991 e desde 2014 já não possui condições de atender à demanda do serviço. Entende-se que o veículo ideal para atender a finalidade da biblioteca móvel seja um ônibus, modelo urbano, pois o caminhão apresenta diversas desvantagens, sobretudo, a restrição de circulação em vias urbanas. 
Figura 1 - Carro-Biblioteca atual da Biblioteca Pública Estadual de Minas Gerais.

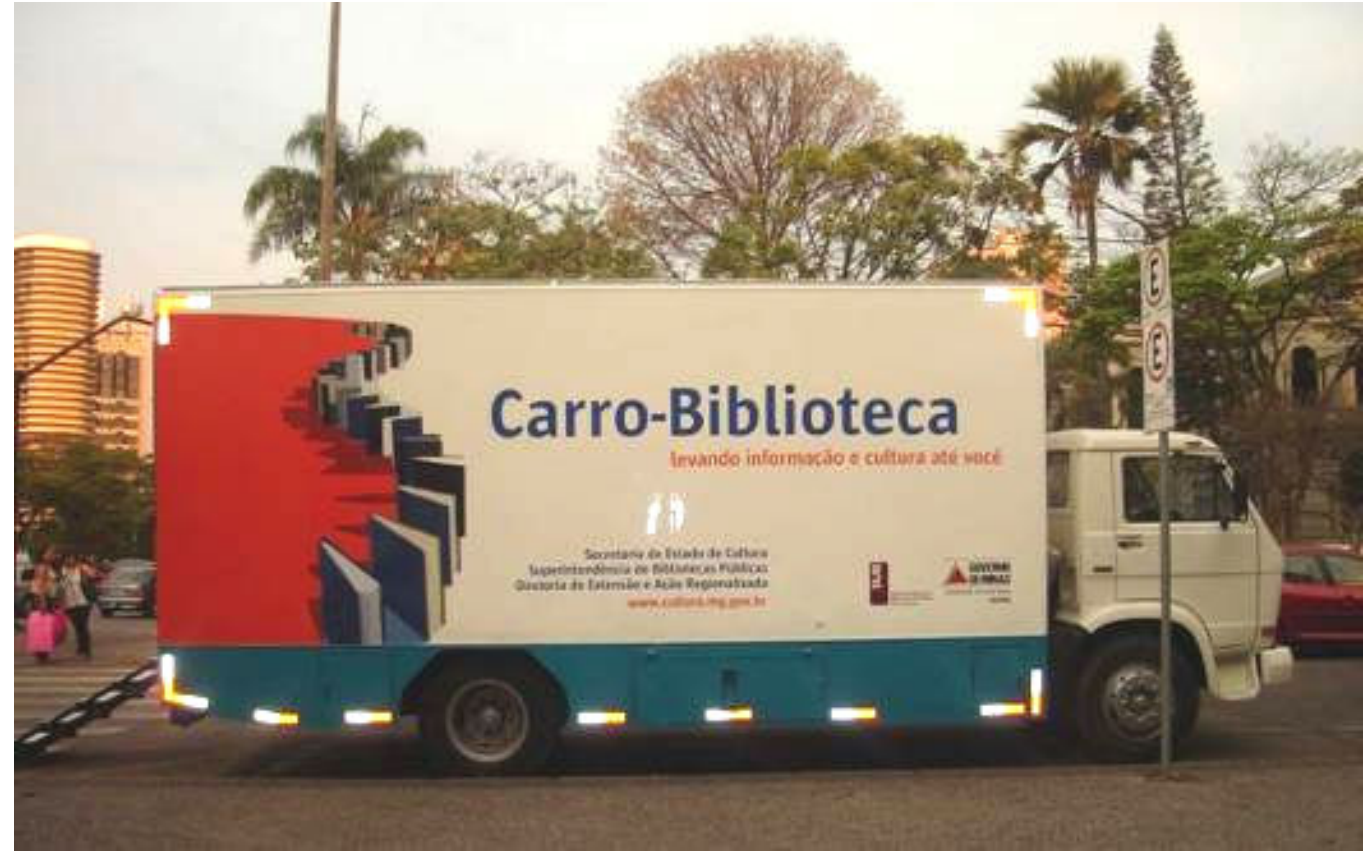

Fonte: Acervo das autoras.

Desde 2015, em parceria com o Laboratório de Estudos Integrados em Arquitetura, Design e Estruturas, da Universidade Federal de Minas Gerais, pesquisas vêm sendo conduzidas, visando o redesign do Carro-Bilblioteca, não somente no sentindo de readaptar o acervo bibliográfico ao chassi e carroceria de um ônibus, mas, sobretudo, de permitir a melhoria do atendimento itinerante da biblioteca para seus usuários, compreendendo aqui não somente os leitores, mas também os atendentes.

Os estudos foram realizados sob a abordagem de design centrado no usuário, buscando a ampliação da compreensão quanto às necessidades de uso, bem como os desejos e expectativas dos usuários do Carro-Bilblioteca. Para tanto, foram aplicadas técnicas que permitiram a vivência aprofundada da equipe de projeto junto ao cotidiano de atendimento do Carro-Biblioteca. Em seguida, outras técnicas favoreceram a ampla problematização da experiência dos usuários.

Os resultados obtidos constituem o fundamento das propostas de soluções, em desenvolvimento, que serão implantadas no novo Carro-Biblioteca.

\section{Metodologia}

Os estudos e redesign do Carro-Biblioteca foram conduzidos por equipe constituída de professora coordenadora e duas bolsistas estudantes do Curso de Design da UFMG.

Os estudos foram realizados em duas etapas, compreendendo: a) vivência do cotidiano de atendimento do Carro-Biblioteca e b) problematização da experiência dos usuários.

A primeira etapa compreendeu a vivência aprofundada do cotidiano de atendimento do Carro-Biblioteca. Este momento de imersão correspondeu à aproximação da equipe de projeto ao contexto em questão, com vistas a analisar as perspectivas tanto do cliente (quem solicita o projeto) quanto dos usuários envolvidos (VIANNA et al., 2012). Segundo Murakami et al. (2014, p. 2), "a imersão tem como objetivo o entendimento inicial do problema, com a respectiva 
identificação de necessidades e oportunidades que nortearão a geração de soluções". Assim, o objetivo é identificar o que implica direta e/ou indiretamente na vida das pessoas, leva-se em consideração aspectos positivos e negativos. Desta forma, reflexões são geradas e registradas e, a partir destas, são extraídos insights e conclusões preliminares sobre o tema trabalhado (LIMA et al., 2014).

Nesta etapa foram realizadas observações diretas a partir do acompanhamento pela equipe de projeto, como integrante, do serviço do Carro-Biblioteca. Esta vivência permitiu a identificação de dois grupos de usuários: os atendentes (incluindo o motorista) e os leitores. A partir de então, foram realizadas entrevistas semi-estruturas junto aos atendentes e motorista, e foram aplicados questionários em escala hedônica junto aos leitores.

A entrevista é uma técnica de coleta de dados que tem a finalidade de obter informações do entrevistado por meio de um roteiro pré-estabelecido. A entrevista semi-estruturada permite que os questionamentos sejam feitos de maneira mais espontânea, favorecendo respostas livres do entrevistado e potencializando a atuação do entrevistador. A entrevista valoriza a fala individual, revelando representações de um grupo (TRIVIÑOS, 1997; LIMA, ALMEIDA e LIMA, 1999; HAUGUETTE, 2011).

A escala hedônica é uma técnica que permite obter a opinião das pessoas a partir da manifestação subjetiva sobre sua preferência: se determinada situação (ou produto) agrada ou desagrada, se é aceito ou não. O objetivo é extrair expressões dos usuários sem utilizar descrição analítica, levando-se em conta apenas o aspecto de preferência, mais ou menos intenso. A escala hedônica pode ser estruturada em, 5, 7 ou 9 pontos. $O$ julgador avalia, entre as opções, a que mais Ihe agrada (TEIXEIRA, 2009; ISAAC, V. et al. 2012; MORAIS, 2012).

Em seguida, as necessidades foram analisadas e hierarquizadas - usuários diferentes têm necessidades diferentes e produtos precisam ser projetados de acordo com tais necessidades (ROGERS, SHARP, PREECE, 2013).

Complementarmente, procedeu-se a uma análise das tarefas a fim de entender os esforços necessários ao desempenho das funções durante o uso do Carro-Biblioteca. A análise da tarefa consiste em analisar e constatar as atividades realizadas pelos usuários por meio de observação, explorando as interações entre o produto e seu usuário (BAXTER, 2000).

A segunda etapa buscou problematizar a experiência dos usuários, objetivando ampliar a compreensão sobre os usuários a partir de técnicas de criatividade que extrapolassem a abordagem analítica adotada na primeira etapa. Para tanto, foram aplicadas técnicas de criação de personagem, de análise funcional, e grupo focal.

A criação de personagens é uma técnica criativa que utiliza "pessoas fictícias para representar usuários de um serviço ou produto. As personas estão inseridas em cenários, histórias, que representam situações reais de uso" (PEREIRA et al., 2015, p. 416). Segundo Carvalho et al. (2011 apud SOUZA, 2014, p. 37) o uso da técnica permite "identificar desejos, necessidade e restrições das pessoas com o objetivo de gerar ideias para criar produtos inovadores".

A análise funcional foi realizada a partir da aplicação da técnica de brainstorming que favorece o aumento da "qualidade e a quantidade das ideias geradas pelos membros do grupo" (BUCHELE et al., 2015, p. 9). Brainstorming é uma técnica de criatividade muito empregada no 
meio corporativo devido ao seu baixo custo e produtividade de resultados. Segundo Gaião Filho e Campos $(2015$, p.13) é um modo de impulsionar ideias sem restrições, aumentando o potencial criativo daqueles que estão realizando a técnica. Segundo os autores "a técnica consiste na interação de indivíduos em grupo para gerar várias ideias de forma livre e não-crítica".

Um "grupo focal" foi organizado para o aprofundamento da compreensão quanto às necessidades e desejos de toda a equipe do Carro-Biblioteca, incluindo dirigentes e outros envolvidos, além dos atendentes e motorista, que muitas vezes não têm contato com os leitores. O grupo focal é uma técnica que consiste na organização de um pequeno grupo de discussão informal, com o propósito de obter informações de caráter qualitativo em profundidade. Morgan (1997, apud GONDIM, 2003, p. 151) "define grupos focais como uma técnica de pesquisa que coleta dados por meio das interações grupais ao se discutir um tópico especial sugerido pelo pesquisador". Para sua aplicação, o grupo não deve ultrapassar o número de 10 pessoas, a fim de se manter a organização e garantir a participação de todos de maneira eficaz. Inicialmente, um mediador deve apresentar as regras e explicar no que consiste a técnica. Perguntas subjetivas devem ser feitas primeiramente para deixar os participantes descontraídos e garantir sua participação efetiva. Posteriormente, devem ser colocadas as perguntas objetivas (KUNIAVSKY, 2003).

No decorrer do projeto a interação com os usuários foi mantida, tendo em vista que a interação é um processo inevitável, já que os projetistas nunca encontram a solução para o problema na primeira vez (GOULD e LEWIS, 1985).

\section{Resultados}

\subsection{Vivência do cotidiano de atendimento do Carro-Biblioteca}

\subsubsection{Entrevistas e questionários}

A fim de se obter respostas direcionadas à realidade dos atendentes (4 pessoas) e do motorista do Carro-Biblioteca, foram realizadas entrevistas semi-estruturadas para direcionar e instigar os funcionários a expressarem suas reais impressões sobre o contexto no qual estão inseridos.

No que tange ao motorista, percebeu-se que suas atividades vão desde preparar o caminhão diariamente para a visita aos bairros até a conferência mecânica do mesmo, a fim de garantir sua condição de prosseguir ou não caminho. O barulho dentro da cabine do caminhão é um dos principais problemas que afeta diretamente o motorista. $O$ barulho é intenso, podendo, em longo prazo, ocasionar prejuízos irreversíveis quanto à saúde auditiva do usuário. Segundo o motorista, a medida mais apropriada para sanar tal problema seria a aquisição de um veículo com chassi de ônibus, mais silencioso e agradável ao dirigir. Outro problema diz respeito ao fato de a cabine reter grande quantidade de calor, e não ter nenhum tipo de ventilação, o que leva a sensações de mal estar e desconforto.

Em relação aos atendentes, vários problemas podem ser observados. Uma das situações mais desconfortáveis (também relatada pelo motorista) diz respeito ao fato de o veículo não possuir local privado para realização do lanche pela equipe de trabalho e uma carência quanto a espaço para que os funcionários possam guardar seus objetos pessoais. Além disto, ao chegar ao bairro de destino, os atendentes devem soltar as diversas faixas utilizadas para fixar os livros nas estantes quando o carro está em movimento, possibilitando o acesso aos livros pelos leitores e, ao 
fim do atendimento, devem prender cada faixa novamente, uma a uma. Outros problemas estão ligados ao mobiliário de atendimento: os materiais de escritório utilizados no atendimento aos leitores ficam acomodados apenas na primeira estação de trabalho; os livros devolvidos pelos leitores ficam improvisadamente em caixas de papelão próximas às mesas dos atendentes; as estações de trabalho são improvisadas.

Outro aspecto extremamente crítico do Carro-Biblioteca é a ventilação. O veículo não possui circulação de ar e é extremamente abafado, provocando até mesmo mal estar aos que permanecem em seu interior, principalmente aos atendentes que nele permanecem por um tempo maior.

Os atendentes identificaram dois problemas que afetam diretamente os leitores: as sinalizações de atendimento em sua maioria não são percebidas pelos leitores; há grande privação ao leitor portador de deficiência locomotora - o carro possui apenas uma entrada feita por uma escada que leva à pequena porta localizada na parte traseira do baú; quando há visita de leitores portadores de deficiência motora, um dos atendentes tem de deslocar-se e realizar o atendimento externo, implicando em constrangimentos para o leitor.

A fim de se obter informações sobre a aceitação pelos leitores quanto ao atual layout do Carro-Biblioteca, foram aplicados 100 questionários em escala hedônica a usuários de diferentes idades, crianças e adultos. Os questionários continham 16 questões que abrangiam desde a experiência dos leitores dentro do veículo, aspectos estruturais do layout, até questões sobre o que os usuários achavam do atendimento e a aceitação do acervo disponível. As respostas para cada questão variavam em escala de 5 pontos entre muito ruim, ruim, indiferente, bom e muito bom. "Bom".

O Gráfico 1 mostra que 80,5\% das respostas concentram-se nas opções "Muito bom" e

Gráfico 1 - Avaliação em Escala Hedônica com base no total de respostas obtidas.

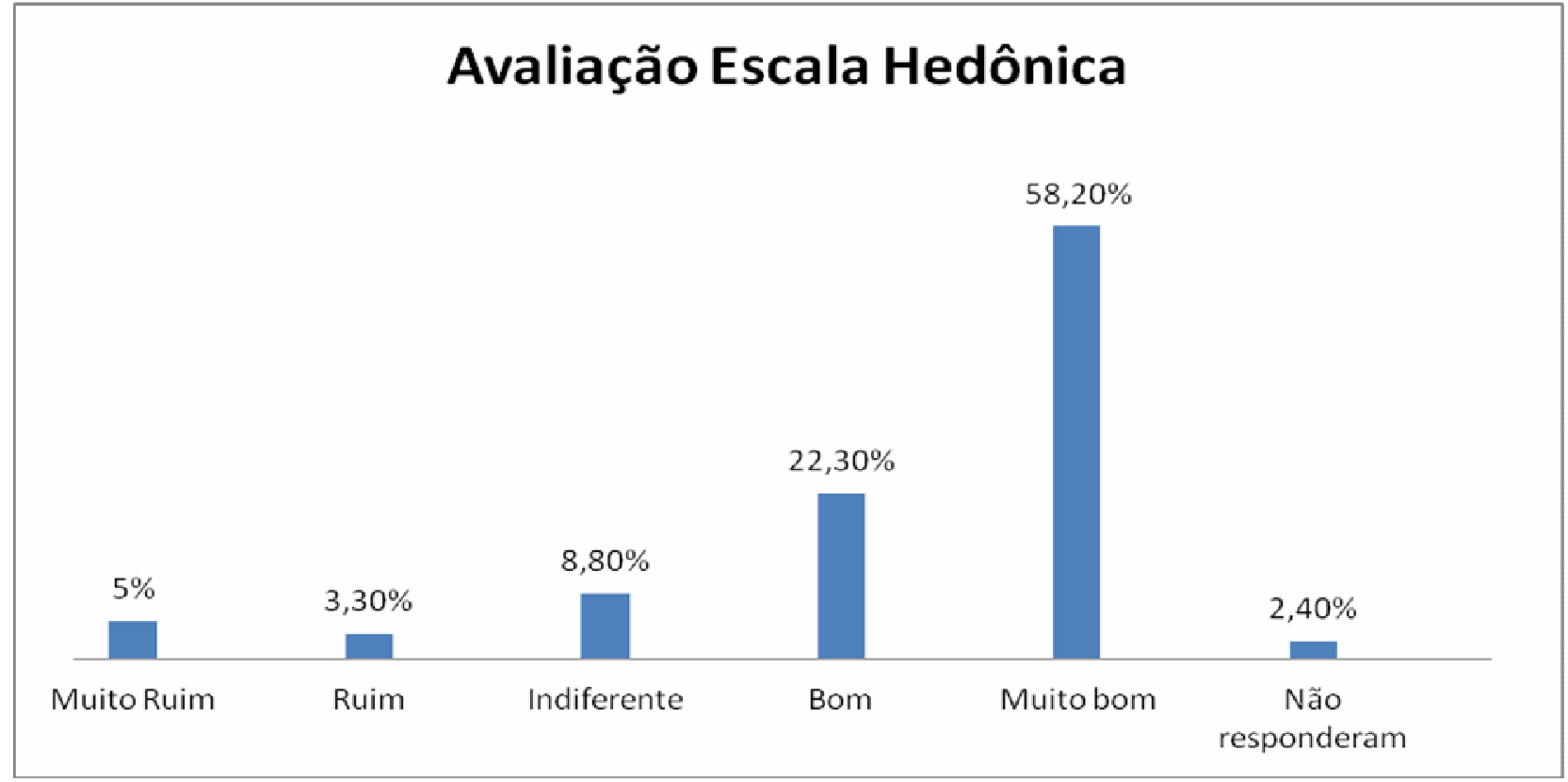

Fonte: Dados da pesquisa. 
Após o tratamento dos dados obtidos com os questionários, observou-se alto grau de aceitação do Carro-Biblioteca em grande parte dos aspectos abordados na pesquisa.

Pôde-se perceber que aspectos mais subjetivos como o gosto pelos livros e revistas, o atendimento e a aceitação quanto ao ambiente, obtiveram elevado grau de satisfação por parte dos leitores, concentrando grande quantidade de respostas na opção "Muito bom".

Porém, aspectos físicos, como o fato de o atendimento ser realizado manualmente e o suporte para as revistas, foram colocados como "Ruim". Outros, como a ventilação dentro do caminhão, a posição das estações de trabalho, o acesso ao caminhão e o sistema de fixação dos livros, foram considerados como sendo "Muito ruim".

Cabe destacar que foi possível perceber, por meio das respostas obtidas com os questionários, bem como com a observação em campo, o quanto o Carro-Biblioteca contribui para o engajamento na leitura de dezenas, e mesmo centenas de pessoas, e a satisfação dos leitores.

\subsubsection{Observações diretas}

A equipe de projeto acompanhou os serviços do Carro-Biblioteca, participando do atendimento aos bairros, observando as atividades dos atendentes e motorista, percebendo cada ação realizada pelos mesmos e pelos leitores, como também realizou os serviços que os funcionários fazem em seu cotidiano, tais como empréstimos de livros, montagem das estantes, realização de novas carteirinhas entre outros.

As observações anotadas muitas vezes coincidem com as conclusões das entrevistas e questionários, apresentados anteriormente, e outras vezes as complementam, como colocado abaixo e apresentado na Figura 2.

Figura 2 - As imagens mostram estações de trabalho adaptadas, uma delas posicionada em frente às estantes; caixa de papelão improvisada para armazenar livros devolvidos; ventilador adaptado; faixas de fixar livros expostas; inacessibilidade.
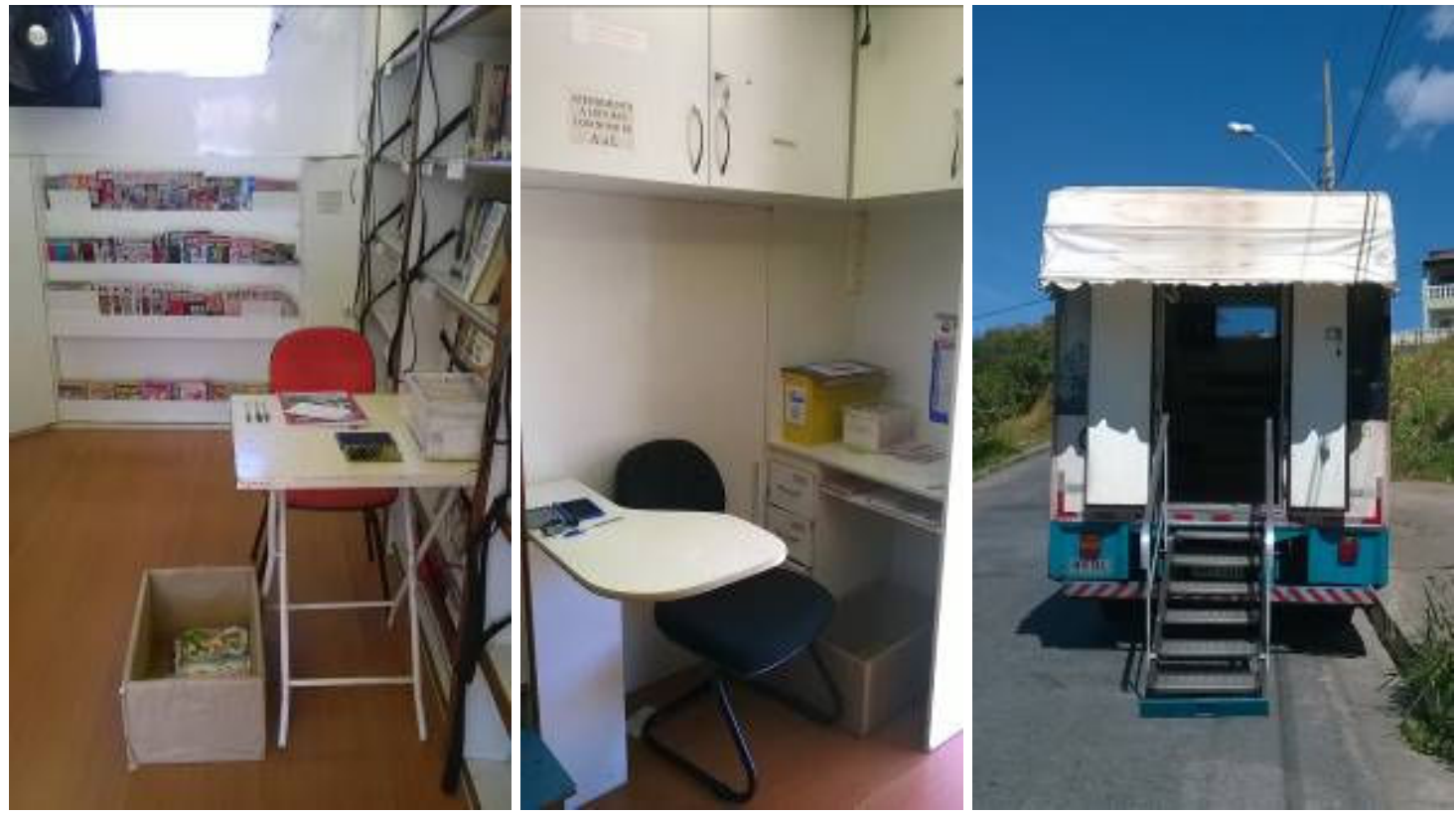

Fonte: Acervo das autoras. 
Estantes: a maneira como os livros são mantidos nas estantes (por meio de uma faixa que transpassa as estantes) não contribui para conservação dos mesmos - os livros possuem diferentes tamanhos dificultando a maneira como são dispostos e presos ao veículo. As faixas não garantem que os livros fiquem em seus respectivos lugares e, caso as estantes não estejam cheias, aumenta a dificuldade de mantê-los presos. Além disto, esse método de fixar os livros exige que os atendentes realizem grande esforço de montar e desmontar todas as vezes que as estantes são utilizadas pelos leitores. Após as estantes serem desmontadas para o uso, as faixas ficam soltas e expostas.

Estações de trabalho: estas não foram planejadas, não estão fixas ao veículo, e por isso não possuem local para "guardar" o material utilizado no serviço. Além disto, necessitam de caixas de papelão improvisadas que servem para armazenar os livros devolvidos e posicionam-se em frente às estantes, prejudicando o acesso ao acervo. Também requerem esforços dos atendentes para serem montadas e desmontadas para o uso.

Inacessibilidade: O carro não possui adaptação para dar acesso e atender usuários que possuam deficiência motora.

Área privativa: não há um espaço para realização das atividades pessoais dos funcionários - não há um local para realizarem suas refeições e não possui sanitário. As gavetas que servem para acomodar os objetos pessoais dos funcionários é distante de suas estações de trabalho.

Aspectos ambientais: ventilação, iluminação, acústica não são adequadas para permanecerem por três horas e trinta minutos ininterruptos de trabalho e leitura.

Dependência do carro: o veículo não possui energia elétrica própria, dependendo de um ponto de apoio para o funcionamento do mesmo.

Informações sobre o serviço: as normas/avisos do Carro-Biblioteca e as classificações dos livros são pouco visíveis.

Percebeu-se que uma das estações é posicionada no meio do caminhão, prejudicando a movimentação e o acesso aos livros. A organização do ônibus exige que os atendentes façam grandes esforços para montar-desmontar e organizar os materiais, demandando mais de trinta minutos para a organização.

Os leitores exigem um serviço rápido, em certos momentos há um acúmulo de livros devolvidos a serem guardados e a uma sobrecarga sobre os atendentes, que não conseguem responder aos leitores como o desejado.

Por outro lado, os leitores são engajados, participam das atividades propostas, gostam de saber quais são os livros novos, contar sobre a vida pessoal, e permanecem dentro do carro com outros interesses para além do serviço de empréstimo.

Em seguida, as necessidades foram analisadas e hierarquizadas de acordo com sua importância, sendo: necessidades primárias aquelas que devem ser priorizadas; necessidades secundárias as que devem ser levadas em consideração após as primárias; necessidades latentes que surgem a partir das reflexões e problematização da experiência dos usuários.

O Quadro 1 mostra a análise e hierarquização das necessidades. 
Quadro 1- Hierarquização das necessidades

\begin{tabular}{|c|c|c|}
\hline Primária & Secundária & Latente \\
\hline $\begin{array}{l}\text { Estantes: disposição dos livros, que caem } \\
\text { com o veículo em movimento, se não } \\
\text { houver as faixas; } \\
\text { Estações não planejadas: localização } \\
\text { atrapalha o acervo; exigem esforço de } \\
\text { montar e desmontar a cada utilização; } \\
\text { possui o risco de se movimentarem em uso, } \\
\text { pois não estão fixas; não possuem locais } \\
\text { para guardar os materiais utilizados; } \\
\text { Inacessibilidade para cadeirantes etc.; } \\
\text { Área privativa: não há um espaço para } \\
\text { realização das atividades pessoais, tais como } \\
\text { refeições, banheiro; } \\
\text { Aspectos ambientais: ventilação, } \\
\text { iluminação, acústica; } \\
\text { Informação: normas e classificação dos } \\
\text { livros ficam pouco visíveis aos leitores. }\end{array}$ & $\begin{array}{l}\text { Estantes: exigem esforço de } \\
\text { montar e desmontar; } \\
\text { visualmente desagradável, pois } \\
\text { as faixas ficam soltas no interior } \\
\text { do veículo; } \\
\text { Caixas para receber livros } \\
\text { devolvidos: os livros utilizados } \\
\text { não possuem local determinado, } \\
\text { e são colocados em caixas } \\
\text { reutilizadas de papelão; } \\
\text { Gavetas e armários: posicionam- } \\
\text { se distantes das estações para } \\
\text { acomodação de objetos de } \\
\text { trabalho e pessoais. }\end{array}$ & $\begin{array}{l}\text { Conservação dos livros: } \\
\text { diferentes tamanhos de livros } \\
\text { que acabam danificando com } \\
\text { tempo, além disso se a estante } \\
\text { não estiver completa, os livros se } \\
\text { movimentam durante traslado do } \\
\text { veículo; } \\
\text { Local para livros e assinaturas } \\
\text { doados: não possui lugar para } \\
\text { guardar os livros doados; } \\
\text { Dependência do ponto de apoio: } \\
\text { depende de estar próximo a } \\
\text { locais que possam fornecer } \\
\text { energia e apoio ao carro. }\end{array}$ \\
\hline
\end{tabular}

Fonte: Dados da pesquisa.

De maneira complementar, foi realizada uma análise da tarefa com o objetivo de se apreender outros detalhes não percebidos a partir das técnicas aplicadas anteriormente. A dinâmica de funcionamento do Carro-Biblioteca se dá da seguinte maneira:

a) Abrir o caminhão: retirar a escada, o toldo, colocar ventilador e estações de trabalho nos devidos locais;

b) Ligar a energia do carro;

c) Organizar os materiais e tirar as faixas dos livros;

d) Começar o atendimento;

e) Fazer empréstimo, fazer carteirinhas e receber devoluções;

f) Indicar e procurar livros, indicar as atividades mensais;

g) Guardar livros da devolução (em certos momentos há um acúmulo de livros e os mesmos precisam ser guardados);

h) Fechar o ônibus, desmontar as estações de trabalho, recolher a escada, tirar o toldo, o ventilador, desligar a energia, colocar as faixas nos livros e guardar os materiais.

O leitor entra no ônibus faz a devolução e/ou empréstimo e ainda permanece olhando os livros, conversando, tirando dúvidas.

A Figura 3 mostra uma visão global do interior do Carro-Biblioteca após preparo à espera da chegada dos leitores e a Figura 4 mostra leitora escolhendo livros para empréstimo. 
Figura 3 - Carro-Biblioteca e funcionários preparados para receber leitores.

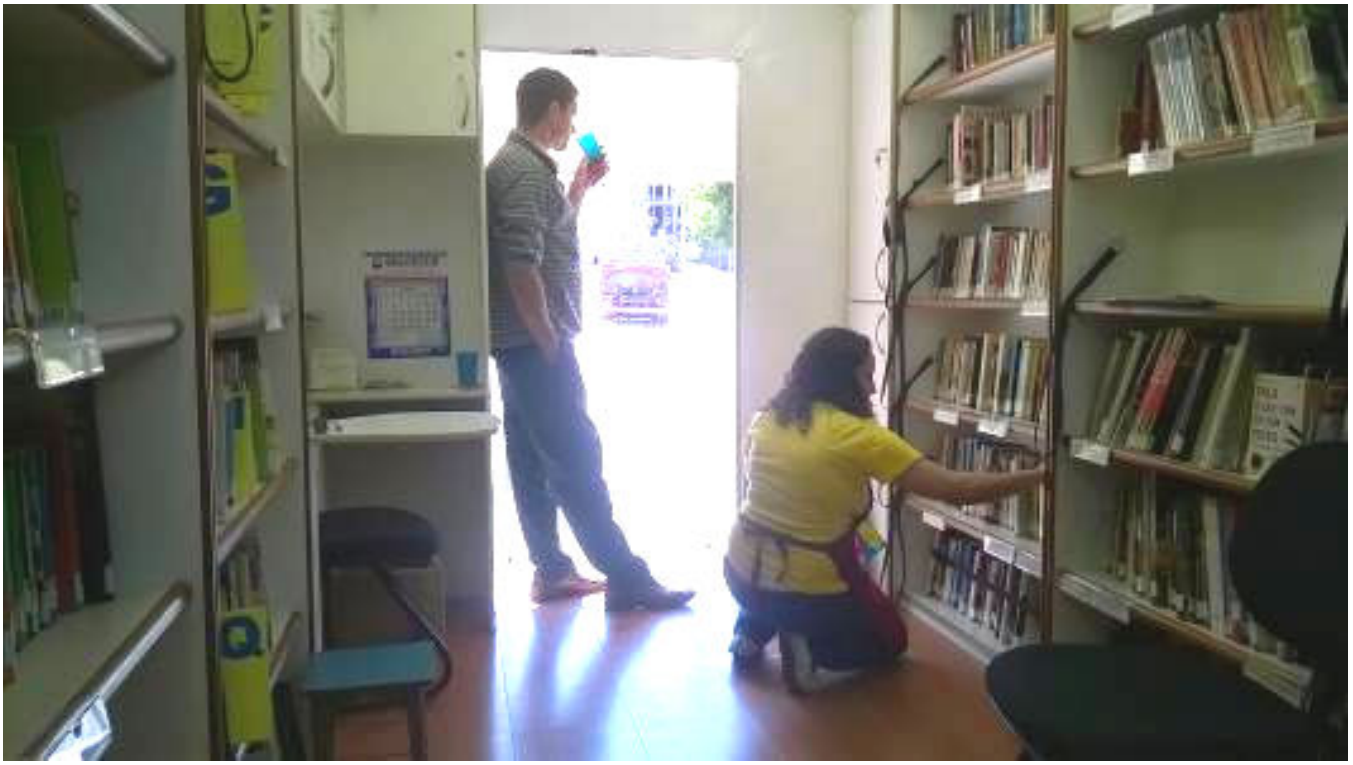

Fonte: Acervo das autoras.

Figura 4 - Leitora escolhe livros para empréstimo.

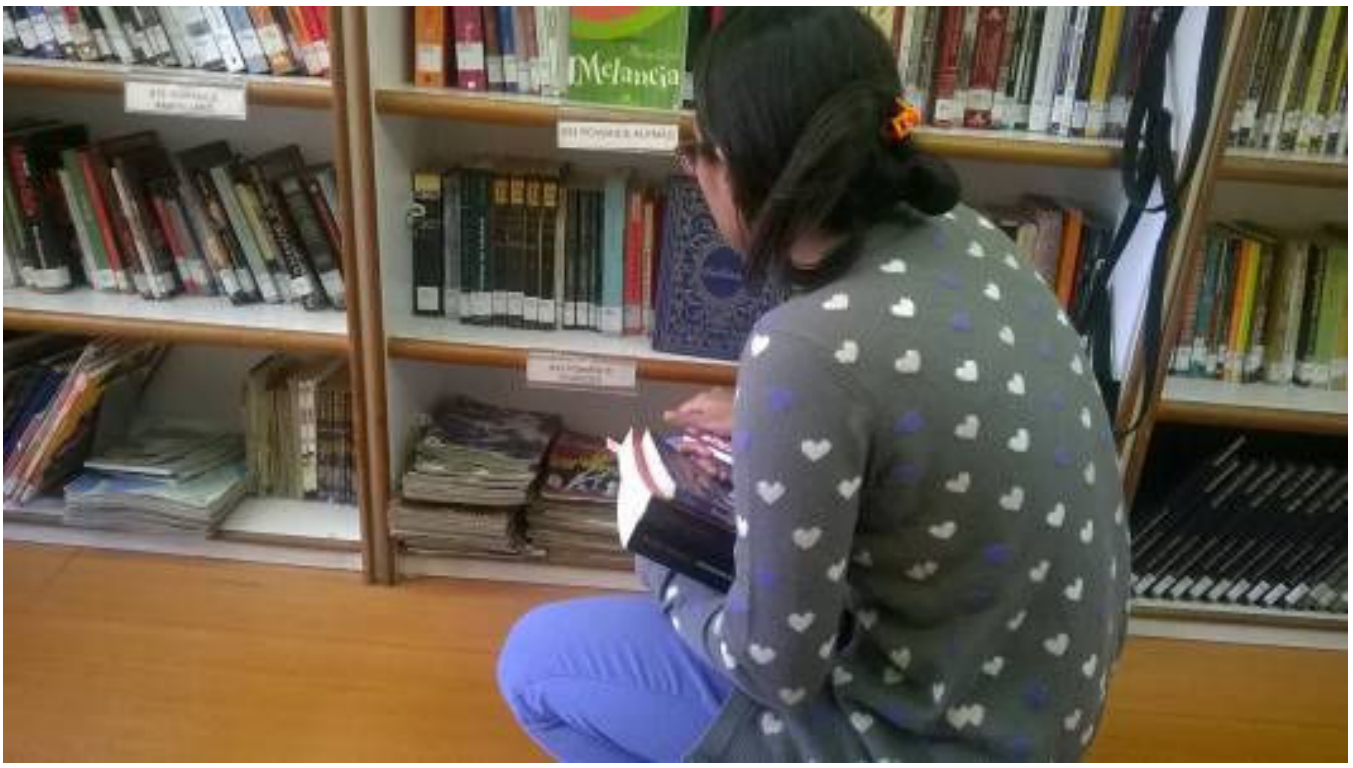

Fonte: Acervo das autoras.

\subsection{Problematização da experiência dos usuários}

\subsubsection{Criação de personagens}

Definir o usuário é necessário para entender a quem o produto se destina. Após a etapa de imersão, dois grupos de usuários foram identificados: os atendentes e motorista (funcionários) e os leitores, para os quais foram criados personagens, permitindo maior aprofundamento quanto às suas necessidades, expectativas e desejos. 
Os funcionários (atendentes e motorista) têm idade aproximada entre 40 e 50 anos e são responsáveis pelo atendimento à população e pela organização do Carro-Biblioteca.

"Juliane sai com o Carro-Biblioteca, chegando ao bairro Minas-Caixa, na região metropolitana de Belo Horizonte, retira as faixas das prateleiras, organiza o material de trabalho e começa o atendimento. Ela precisa ajudar os leitores a encontrar os livros nas prateleiras, indicar livros novos, conduzir o empréstimo e a devolução. No meio do período ela sente fome, mas precisa esperar os leitores saírem para lanchar rapidamente antes que outros leitores cheguem. Quando tudo acaba ela precisa guardar os livros devolvidos, organizar o material de trabalho, fechar as estantes com a faixa, enquanto o motorista irá ao ponto de apoio desligar a energia."

Os leitores são adultos, jovens e crianças de idades variadas que moram no bairro e esperam ansiosamente a chegada do Carro-Biblioteca.

Maria entra no Carro-Biblioteca com sua filha, deseja ler um novo livro, mas ainda não sabe qual. Então, pede sugestões de livros para ela própria e um livro específico para sua filha, Amanda, e precisa de ajuda de algum atendente para encontrá-los. Depois precisa realizar o empréstimo. Elas ainda permanecem no carro para colocar o assunto em dia com os amigos e funcionários do Carro-Biblioteca.

\subsubsection{Análise funcional}

A análise funcional pode mostrar ao designer como os consumidores enxergam o produto e como o utilizam, provocando o aparecimento de novos conceitos interessantes (LACHNITT, 1994; ABREU, 1995; CSILLAG, 1995; VARGAS, 2002).

Primeiramente, optou-se pela aplicação da técnica de brainstorming, com o objetivo de se gerar ideias sobre quais são as funções, mas também as disfunções, do Carro-Biblioteca. Em seguida, essas funções e disfunções foram classificadas e analisadas.

O mediador apresentou o contexto à equipe de projeto, estipulando 10 minutos para que o máximo de funções fosse sugerido pela equipe e mais 10 minutos para que fosse sugerido o máximo de disfunções. O mediador anotou todas as funções e disfunções que surgiram e, posteriormente, as mesmas foram analisadas e classificadas. Assim, as funções foram classificadas como "função de uso" e "função de estima" tendo sido organizadas nestas duas categorias e de acordo com seu grau de importância.

As funções de uso (também denominadas funções práticas) referem-se aos aspectos fisiológicos do produto, englobando as funções técnicas relacionadas ao manuseio e entendendo o usuário como utilizar do produto (BÜRDEK, 2006). As funções de estima (CSILLAG, 1995) (também denominadas funções simbólicas) são determinadas por todos os aspectos espirituais, psíquicos e sociais que entram em jogo durante a interação do uso com o produto. A função simbólica ocorre no nível dos processos sensoriais e é responsável "por atribuir características de estima ao usuário na experiência de uso" (CAMPOS, 2014 p. 61). Significados simbólicos somente podem ser interpretados a partir de contextos socioculturais, que acabam atuando como pano de fundo, representando os diferentes contextos dessa interação usuário/produto (BÜRDEK, 2006).

O Quadro 2 mostra a classificação das funções de uso e de estima. 
Quadro 2- Classificação das funções de uso e de estima.

\begin{tabular}{|l|l|}
\hline \multicolumn{1}{|c|}{ Funções de uso } & \multicolumn{1}{c|}{ Funções de estima } \\
\hline $\begin{array}{l}\text { Principais: } \\
\begin{array}{l}\text { Prestar serviço público; comunicar; emprestar; atender } \\
\text { as comunidades; criar condições favoráveis; } \\
\text { democratizar; transportar livros; guardar livros; permitir } \\
\text { acesso, levar leitura até as pessoas; proteger os livros; } \\
\text { conservar livros; armazenar Livros; permitir conforto. }\end{array}\end{array}$ & $\begin{array}{l}\text { Principais: } \\
\text { Ler; entreter; comunicar; incluir; educar; transformar; } \\
\text { atingir/sensibilizar as pessoas; democratizar; divulgar; } \\
\text { facilitar; ser agradável; aproximar; incentivar; permitir } \\
\text { conforto. }\end{array}$ \\
\hline $\begin{array}{l}\text { Secundárias: } \\
\begin{array}{l}\text { Unir os livros; transformar; estudar (obrigações de } \\
\text { estudar); alfabetizar; educar; trabalhar; disseminar } \\
\text { cultura. }\end{array}\end{array}$ & $\begin{array}{l}\text { Secundárias: } \\
\text { Unir; transformar; brincar; estudar; viajar; empoderar; } \\
\text { conversar/socializar; desenhar; alfabetizar; iluminar; } \\
\text { despertar; crescer; rir; trabalhar; conhecer culturas; } \\
\text { criar; participar; integrar; desenvolver; vivenciar; } \\
\text { sonhar; transbordar conhecimento; agregar; incentivar; } \\
\text { superar; mudar; aprender; alegrar. }\end{array}$ \\
\hline
\end{tabular}

Fonte: Dados da pesquisa.

O Quadro 3 mostra a classificação das disfunções de uso e de estima.

Quadro 3- Classificação das disfunções de uso e de estima.

\begin{tabular}{|l|l|}
\hline \multicolumn{1}{|c|}{ Disfunções de uso } & \multicolumn{1}{c|}{ Disfunções de estima } \\
\hline $\begin{array}{l}\text { Principais: } \\
\text { Deixar livros caírem; machucar; apertar: não ter espaço; } \\
\text { esquentar; atrapalhar acesso; dificultar acesso; impedir } \\
\text { acesso; faltar apoio: infraestrutura; faltar informação; } \\
\text { entregar os livros; ser desconfortável. }\end{array}$ & $\begin{array}{l}\text { Principais: } \\
\text { Confundir: insegurança; inibir. }\end{array}$ \\
\hline $\begin{array}{l}\text { Secundárias: } \\
\text { Confundir; inibir; desordenar; obstruir trânsito; não } \\
\text { democratizar serviço; incomodar; fazer barulho. }\end{array}$ & $\begin{array}{l}\text { Secundárias: } \\
\text { Irritar, desapontar; passar despercebido; deixar as } \\
\text { pessoas na mão. }\end{array}$ \\
\hline
\end{tabular}

Fonte: Dados da pesquisa.

\section{A análise das funções pode ser assim resumida:}

Funções de uso: serviço para os bairros de Belo Horizonte, oferecendo uma biblioteca itinerante à população, a partir do empréstimo de livros. Dentro do veículo existem duas estações de trabalho para realizar o serviço e estantes para armazenar os livros.

Funções de estima: o veículo deve apresentar layout interno e externo convidativos para chamar o leitor a vivenciar os serviços do Carro-Biblioteca e proporcionar melhor experiência para o usuário, de maneira transformadora, de entretenimento e aprendizado, acolhendo e aproximando as pessoas.

Além das funções de uso e estima, evidenciou-se, em particular, a função ergonômica que diz respeito ao "modo de uso do produto e sua operacionalidade" (CAMPOS, 2014, p. 61). 
Funções de ergonômica: a infraestrutura do veículo como é hoje organizada exige grande esforço dos funcionários que devem montar e desmontar o mesmo em todos os dias de uso. Deve também fazer esforços para procurar os livros e atender à população, sem que haja espaço restrito e adequado para tanto.

\subsubsection{Grupo focal}

Uma sessão de "grupo focal" foi realizada com seis convidados: o superintende de Bibliotecas Públicas e Suplementos Literários, a diretora de Extensão e Ação Regionalizada, a coordenadora do Carro-Biblioteca, os atendentes/mediadores de leitura e o motorista do carro, estes últimos, que possuem ligação próxima com o quotidiano do Carro-Biblioteca, vivenciando a rotina e compreendendo em profundidade a situação atual do veículo. Contou ainda com a mediação da coordenadora do projeto e de bolsista, que tomou notas de toda a sessão.

A aplicação da técnica se baseou em nove perguntas, como mostra o roteiro no Quadro 4.

Quadro 4- Roteiro para Grupo Focal

\begin{tabular}{|c|}
\hline $\begin{array}{l}\text { Perguntas subjetivas: } \\
\text { - O que significa pra vocês o Carro-Biblioteca? } \\
\text { - Que atividades/esforços vocês realizam no Carro-Biblioteca? } \\
\text { Perguntas objetivas: } \\
\text { CONDIÇÕES DE USO E PERCEPÇÕES } \\
\text { - O Carro atende as necessidades de vocês? ou seja, É possível realizar todas as atividades } \\
\text { - } \quad \text { necessárias ? } \\
\text { - do Carro-Biblioteca? } \\
\text { - O que vocês acham desagradável no Carro-Biblioteca? } \\
\text { ASPIRAÇÕES } \\
\text { - Quais aspectos (funcionários e leitores) com o Carro-Biblioteca? } \\
\text { - Quais serviços pretendem oferecerto }\end{array}$ \\
\hline
\end{tabular}

Fonte: Dados da pesquisa.

Antes de serem colocadas as perguntas para o grupo, foi explicado, pela mediadora, quanto aos objetivos e características da técnica de grupo focal e, em seguida, foram apresentadas as regras da dinâmica: respeitar a privacidade dos participantes, evitar repetir o que já foi dito, cada pessoa deve falar por vez, respeitar a opinião do outro, não criticar, não rejeitar e não dirigir olhar de estranhamento ou desdém para nenhum comentário. Cada pessoa deve ter a mesma oportunidade de fala. Após a introdução das regras, a mediadora pediu para que todos se apresentassem e falassem sobre sua atuação no Carro-Biblioteca.

Após esta fase, primeiramente, foram colocadas para o grupo as perguntas subjetivas, com objetivo de descontrair os participantes e incentivar a participação de todos. Em seguida, as perguntas objetivas foram colocadas, com o objetivo de se entender sobre a percepção do grupo em relação às condições atuais do Carro-Biblioteca, bem como sobre suas expectativas para o futuro. Finalmente, como encerramento, a mediadora solicitou que todos os participantes 
expressassem como seria o "Carro-Biblioteca dos sonhos". Assim, todos participaram da discussão, relatando como seria um veículo ideal.

Posteriormente, a bolsista transcreveu a reunião, registrada por meio de gravador de um aparelho celular, com a autorização de todos os presentes. A partir da transcrição, foram feitas observações baseadas nos pontos ressaltados pelos participantes.

Ressalta-se o envolvimento emocional dos participantes com relação ao Carro-Biblioteca: houve uma demonstração de satisfação e de orgulho em se levar o hábito de leitura às pessoas, sendo possível extrair dos depoimentos o quanto é importante o projeto do Carro-Biblioteca para todos os participantes.

Quanto aos problemas de uso relatados, os mesmos coincidem com as observações feitas anteriormente.

Em relação ao "sonhos" quanto ao Carro-Biblioteca ideal, a maioria das opiniões expressas dizem respeito ao conforto do uso quotidiano do Carro (instalação de ar condicionado, banheiro, local reservado para atendentes, carro novo em bom estado de conservação); e ao atendimento ao público, ampliando ações mais interativas com leitores, tais como apresentação de sessão de vídeos, cinema etc.

\section{Conclusão}

O Carro-Biblioteca atende a bairros na periferia de Belo Horizonte, desprovidos de equipamentos culturais. Atualmente, o atendimento é feito em veículo adaptado em caminhão baú, inadequado ao tráfego urbano e apresentando diversos inconvenientes em termos de conforto ambiental.

Para atender às necessidades de todos os usuários, incluindo público leitor, atendentes e motorista, a adaptação deverá contemplar vários itens. Análises foram feitas junto aos usuários para identificação de suas necessidades no uso cotidiano do Carro-Biblioteca: questionários em escala hedônica junto aos leitores; entrevistas semi-estruturadas com atendentes e motoristas; vivência aprofundada do cotidiano de atendimento do Carro-Biblioteca; problematização da experiência dos usuários; grupo focal com toda equipe do Carro-Biblioteca na Biblioteca Pública Estadual de Minas Gerais.

Propõe-se a adaptação do Carro-Biblioteca em ônibus, que permitirá, não somente melhor adequação ao traslado, como também melhor disposição do acervo, espaço e equipamentos e melhor circulação do público leitor.

Diante das análises realizadas, a adaptação deverá conter os seguintes equipamentos:

- ar condicionado para conforto térmico;

- elevador para cadeirantes, permitindo maior acessibilidade;

- monitor para atividades interativas com público leitor;

- instalação de áudio e microfone para atividades interativas com público leitor;

- lâmpadas com iluminamento entre 400 e 600 lux para leitura;

- sanitário para atendentes e motorista;

- frigobar e microondas para lanche de atendentes e motorista;

- instalação elétrica para notebooks, a fim de registrar empréstimos dos livros;

- toldo para ampliação da área externa e maior conforto dos usuários. 
Além disto, o maior espaço apresentado pela carroceria de um ônibus favorecerá a ampliação do acervo em 32\%, passando de 4200 para aproximadamente 5550 obras, e permitirá a realização de atividades interativas tais como bate-papo com o escritor e contação de estórias em seu espaço interno. O ônibus permitirá, ainda, no futuro, a organização de atividades nos demais municípios do Estado de Minas Gerais, visto sua capacidade de circulação em rodovias.

\section{Agradecimentos}

Agradecimentos à FAPEMIG - Fundação de Amparo à Pesquisa do Estado de Minas Gerais e ao CNPq - Conselho Nacional de Desenvolvimento Científico e Tecnológico pelos recursos concedidos, que permitiram a realização desta pesquisa.

\section{Referências}

ABREU, R. C. L. Análise de valor: um caminho criativo para a otimização dos custos e do uso dos recursos. Rio de Janeiro: Qualitymarth, 1995.

BAXTER, M. Projeto do Produto: guia prático para o design de novos produtos. Blucher, 2008.

BUCHELE, G. T.; TEZA, P.; DANDOLINI, G. A.; SOUZA J. A. de. Métodos, técnicas e ferramentas para inovação: brainstorming no contexto da inovação. VII Seminário de Pesquisa Interdisciplinar, UNISUL, 2015. Disponível em: <http://www.unisul.br/wps/wcm/connect/95eb03a8-996f-4d7889e7-e2982649e942/artigo_gt-adm_gustavo-pierry-gertrudes-joao_vii-spi.pdf?MOD=AJPERES> Acesso em: 26 fev. 2017.

BÜRDEK, B. E. Design - História, teoria e prática do design de produtos. São Paulo: Blücher, 2006.

CAMPOS, L. F. de A. Usabilidade, percepção estética e força de preensão manual: influência no design ergonômico de instrumentos manuais: um estudo com tesouras de poda. 2014. 289 p. Tese (doutorado) - Universidade Estadual Paulista Julio de Mesquita Filho, Faculdade de Arquitetura, Artes e Comunicação, 2014. Disponível em: <http://hdl.handle.net/11449/126294>. Acesso em: 13 março 2018.

CARVALHO, C. R. de.; COSTA, G. C.; ANDRADE, C. D.; GOMES, A. S.; CYSNE, C. M. B. Unindo IHC e Negócios através do uso de Personas: Um Estudo de Caso no Mercado de Aplicativos Móveis. In IHC+CLIHC, 2011, 100-104. IEEE

CSILLAG, J. M. Análise do valor. 4. ed. São Paulo: Atlas, 1995.

GAIÃO FILHO, I. e CAMPOS, F. Análise comparativa da experiência das técnicas criativas

Brainstorming e Método 635 a partir da Teoria da Atividade. Ergotrip Design: Revista dos encontros internacionais de estudos luso-brasileiros em Design e Ergonomia, v. 1, p.10-19. 2015. Disponível em: <http://revistas.ua.pt/index.php/ergotripdesign/article/view/4103/3978f >. Acesso em: 19 ago. 2016.

GONDIM, S. M. G. Grupos focais como técnica de investigação qualitativa: desafios metodológicos. 2003. In: Paidéia, 2003, 12(24), 149-161. Disponível em: <http://www.scielo.br/pdf/paideia/v12n24/04>. Acesso em: 19 abr. 2017.

GOULD, J. D. e LEWIS, C. Designing for usability: key principles and what designers think. Communications of the ACM 28, 3, 300-311, 1985.

HAGUETTE, T. M. F. Metodologias qualitativas na sociologia. 14.ed. Petrópolis, RJ: Vozes, 2011. 
ISAAC, V. et al. Análise sensorial como ferramenta útil no desenvolvimento de cosméticos. Rev Ciênc Farm Básica Apl., 2012;33(4):479-488

LACHNITT, J. L'analyse de la valeur. Paris: Presses Universitairesde France, Que sais-je? 1994.

LIMA, A. M.; ALVES, A. T.; COSTA, A. J. S. da.; SALES, E. de O. Metodologia design thinking no projeto de software para mobilidade urbana: relato de aplicação. AtoZ: novas práticas em informação e conhecimento, Curitiba, v. 3, n. 2, p. 128-138, jul./dez. 2014.

http://dx.doi.org/10.5380/atoz.v3i2.41345

LIMA, M. A. D. S; ALMEIDA, M. C. P.; LIMA, C. C. A utilização da observação participante e da entrevista semi-estruturada na pesquisa de enfermagem. Revista gaúcha de enfermagem. Porto Alegre. Vol. 20, n. especial (1999), p. 130-142.

MORAIS, I. C. Preferência do usuário quanto à madeira: estudo de aspectos subjetivos de escolha, utilizando Análise Sensorial. Dissertação Mestrado em Ambiente Construído e Patrimônio Sustentável. UFMG, 2012.

MORGAN, D. Focus group as qualitative research. Qualitative Research Methods Series. 16. London: Sage Publications, 1997.

KUNIAVSKY, M. Observing the user experience: a practitioner's guide to user research. SanFrancisco: Morgan Kaufmann, 2003.

MURAKAMI, L. C.; LEITE JÚNIOR, A. J. M.; SABINO, R. F. S; MACEDO, D. A. Design Thinking como metodologia alternativa para o desenvolvimento de jogos sérios. In: Nuevas Ideas en Informática Educativa TISE, 1., 2014, p.656- 661. Disponível em: <http://docplayer.com.br/680984-Designthinking-como-metodologia-alternativa-para-o-desenvolvimento-de-jogos-serios.html>. Acesso em: 13 março 2018.

PEREIRA, A. R. S.; SOUZA, C. L. C.; CAVALCANTE, L. M. F.; LEITE, V. B.; PEREIRA JUNIOR, D. Tecnologia Educacional para ensino médio - BibliVirti. In: Anais dos Workshops do IV Congresso Brasileiro de Informática na Educação CBIE, 2015. DOI: 10.5753/cbie.wcbie.2015.414

ROGERS, Y.; SHARP, H.; PREECE, J. Design de interação: além da interação humano-computador. Porto Alegre: Bookman, 2013.

SOUZA, C. L. C. Uso do Design Thinking na elicitação de requisitos de ambientes virtuais de aprendizagem móvel. Dissertação (Mestrado) - Curso de Ciência da Computação, Universidade Federal de Pernambuco, Recife, 2014. Disponível em:

<https://repositorio.ufpe.br/bitstream/handle/123456789/13938/DISSERTAÇÃO Cynara Lira de Carvalho Souza.pdf?sequence=1\&isAllowed=y>. Acesso em: 05 out. 2016.

TEIXEIRA, L. V. Análise sensorial na indústria de alimentos. Rev. Inst. Latic. "Cândido Tostes", Jan/Fev, no 366, 64: 12-21, 2009.

TRIVIÑOS, A. N. S. Introdução à pesquisa em ciências sociais: a pesquisa qualitativa em educação. São Paulo: Atlas, 1997.

VARGAS, R. V. Análise de valor agregado (EVA) em projetos. Rio de Janeiro: Brasport, 2002.

VIANNA, M.; VIANNA, Y.; ADLER, I. K.; LUCENA, B.; RUSSO, B. Design Thinking: inovação em negócios. Rio de Janeiro: MJV Press, 2012. Disponível em: <

http://www.livrodesignthinking.com.br/>. Acesso em: 13 março 2018. 